\title{
Chloroquine Inhibits Self-Renewal of Blast Progenitors Synergistically With Phytochemicals or Nonsteroidal Anti- inflammatory Drugs in Hematological Malignant Cell Lines
}

\author{
NORIKO KAWAGUCHI-IHARA ${ }^{1}$, YAN ZHAO ${ }^{2}$, SUZUNE NAKAMURA ${ }^{1}$, \\ KEIKO SUZUKI $^{1}$, YI ZHANG ${ }^{2}$, SHUJI TOHDA ${ }^{3}$ and IKUO MUROHASHI ${ }^{2,4}$ \\ Departments of ${ }^{1}$ Health Sciences and ${ }^{2}$ Hematology, Center for University-Wide Education, \\ School of Health and Social Services, Saitama Prefectural University, Saitama, Japan; \\ ${ }^{3}$ Department of Laboratory Medicine, Tokyo Medical and Dental University, Tokyo, Japan; \\ ${ }^{4}$ Internal Medicine, Seibu-Iruma Hospital, Saitama, Japan
}

\begin{abstract}
Background: This study examined whether and how chloroquine inhibits blast progenitor self-renewal (SR) synergistically with phytochemicals or nonsteroidal antiinflammatory drugs in seven hematological malignant cell lines. Materials and Methods: Vitamin C, resveratrol, cyclooxygenase inhibitor NS-398 and indomethacin heptyl ester (Ind) were added to cell culture with or without $3 \mu \mathrm{M}$ chloroquine. Results: Chloroquine synergistically inhibited blast colony formation in methylcellulose with vitamin $C$, resveratrol, NS-398 and Ind in one, two, none and one cell lines, respectively, in a total of four out of 28 conditions. Chloroquine synergistically inhibited blast progenitor SR in suspension with vitamin C, resveratrol, NS-398 and Ind in four, six, one and five cell lines, respectively, in a total of 16 out of 28 conditions. In contrast, chloroquine abolished SR inhibition by another agent in four out of 28 conditions. Conclusion: Chloroquine exerted a marked synergistic inhibition of blast progenitor SR, but not blast colony formation.
\end{abstract}

There has been a growing interest in cancer prevention and other therapeutic use of food plants and their products (1-4). The preventive role of nonsteroidal anti-inflammatory drugs (NSAIDs) and aspirin in several cancer types is well established (5-7). Additionally, these studies indicated that the chemopreventive effect is dose- and duration-dependent $(2,6-8)$.

This article is freely accessible online.

Correspondence to: Ikuo Murohashi, MD, Internal Medicine, SeibuIruma Hospital, Noda 3078-13, Iruma-City, Saitama 358-0054, Japan. Tel: +81 429321121, e-mail: murohashi-ikuo@spu.ac.jp

Key Words: Chloroquine, synergistic inhibition, phytochemicals, NSAIDs, blast progenitor self-renewal, hematological malignancies.
Treatment of acute myeloid leukemia (AML) cells with catalytic mammalian target of rapamycin (mTOR) inhibitors resulted in induction of autophagy, which acts as a regulatory mechanism promoting leukemia cell survival $(9,10)$. Simultaneous blockade of the autophagic process using chloroquine or by knockdown of Unc-51 like autophagy activating kinase 1 (ULK1) resulted in enhanced antileukemic responses. Interestingly, NSAIDs and phytochemicals have been shown to inhibit mTOR (11-17) and induce autophagy $(13-15,18,19)$.

In AML and acute lymphoblastic leukemia, leukemia stem cells arise either from hematopoietic stem cells or more differentiated and committed progenitors that acquire the potential for self-renewal (SR) $(20,21)$. The SR of leukemia blast progenitors assessed by secondary blast colony formation $(\mathrm{BCF})$ in methylcellulose or recovery of clonogenic cells (CCs) in suspension (22), but not terminal divisions of blast progenitors assessed by primary BCF in methylcellulose (23), has been described to be highly correlated with the clinical outcome of patients with AML $(24,25)$. Leukemia stem cells not only adopt the regulatory machinery operating in normal hematopoietic stem cells, but also establish their own mechanisms against differentiation and cellular stress responses such as autophagy, apoptosis, necrosis and senescence $(26,27)$.

Thus, in the present study, using our newly-established long-term suspension culture $(28,29)$, the growth of blast CCs was investigated not only in methylcellulose, but also in liquid suspension for up to 4 weeks by serial re-plating following continuous exposure to phytochemicals or NSAIDs with and without chloroquine in seven malignant hematological cell lines. Cellular stress responses, such as autophagy, apoptosis, necrosis and senescence, were also serially determined. To the best of our knowledge, this is the first study which demonstrated that chloroquine in 
combination with phytochemicals or NSAIDs significantly inhibits the SR capacity of malignant stem/progenitor cells compared to either agent alone.

\section{Materials and Methods}

Reagents. Iscove's modified Dulbecco's medium (IMDM), fetal calf serum (FCS) and phosphate-buffered saline (PBS) were from Gibco (Grand Island, NY, USA). Chloroquine and vitamin $\mathrm{C}$ were from Sigma-Aldrich Corporation (St. Louis, MO, USA). Trypan blue (TB) was from Sigma (Tokyo, Japan). Indomethacin heptyl ester (Ind) as a cyclo-oxygenase (COX) 1 and 2 inhibitor [half maximal-inhibitory concentration $\left(\mathrm{IC}_{50}\right)$ for human $\left.\mathrm{COX} 2=0.04 \mu \mathrm{M}\right]$ and COX2-specific inhibitor NS-398 $\left(\mathrm{IC}_{50}=1.77 \mu \mathrm{M}\right)$ were from Cayman Chemical Co. (Ann Arbor, MI, USA). Recombinant human (rh) interleukin-3 (IL3) was a generous gift from Dr. S. Clark (Genetics Institute, Cambridge, MA, USA). Resveratrol was from Biomol International LP (Farmingdale, PA, USA).

Cultured cells were assessed in methylcellulose and suspension with chloroquine alone or in combination with vitamin $\mathrm{C}$, resveratrol, NS-398 and Ind at final concentrations of 3, 300, 10, 30 and $30 \mu \mathrm{M}$, respectively $(28,29)$.

Cell lines. HL-60 (kindly provided by Dr D.W. Golde, UCLA School of Medicine, LA, CA, USA) is a myeloid cell line derived from a patient with acute promyelocytic leukemia. Mo7e (a kind gift of Dr S. Tohda, Tokyo Medical and Dental University, Tokyo, Japan) is a subclone of the human megakaryoblastic-leukemia cell line Mo7 (30). The cells require either IL3 or granulocyte-macrophage colonystimulating factor for long-term growth. K562 is a myeloid cell line derived from a patient with chronic myelogenous leukemia in myeloid crisis. Daudi and Raji are B-lymphoid cell lines derived from patients with Burkitt's lymphoma. U-937 is a human histiocytic, monocyte-like cell line derived from a patient with diffuse histiocytic lymphoma. K562, Daudi, Raji and U-937 were purchased from the Japanese Collection of Research Bioresources Cell Bank (Osaka, Japan). Human myeloma cell line U-266 was kindly provided by Dr M. Kawano (Yamaguchi University School of Medicine, Ube, Japan). Cells were propagated in IMDM with $10 \%$ FCS in the presence or absence of hematopoietic growth factor (HGF) (10 ng/ml rhIL3 for $\mathrm{Mo} 7 \mathrm{e})$, at $37^{\circ} \mathrm{C}$ in a humidified atmosphere containing $5 \% \mathrm{CO}_{2}$.

Long-term suspension culture. To determine the blast clonogenic SR capacity, the growth of blast CCs was investigated in liquid suspension for up to 4 weeks by serial re-plating following continuous exposure to phytochemicals or NSAIDs with and without chloroquine. Briefly, cells were cultured at a density of $2 \times 104 / \mathrm{ml}$ in 35-mm Lux tissue culture dishes (Miles Lab., Naperville, IL, USA) in $2 \mathrm{ml}$ of IMDM with $10 \%$ FCS in the presence or absence of HGF $(10 \mathrm{ng} / \mathrm{ml} \mathrm{rhIL} 3$ for Mo7e) and agents $(28,29)$. Controls contained $0.38 \%$ dimethyl sulfoxide (DMSO) alone. Twice a week, the cells were harvested, counted, washed and plated in 96-microwell plates at a density of $2 \times 10^{3}$ per well in $0.1 \mathrm{ml}$ of IMDM with $1 \%$ methylcellulose and $10 \% \mathrm{FCS}$, in the presence or absence of HGF (10 $\mathrm{ng} / \mathrm{ml} \mathrm{rhIL3} \mathrm{for} \mathrm{Mo7e)} \mathrm{to} \mathrm{obtain} \mathrm{the} \mathrm{plating} \mathrm{efficiency.} \mathrm{The}$ recovery of CCs per dish was obtained by multiplying this plating efficiency by the number of cells harvested from the suspension. At each subculture, the harvested cells were transferred into fresh medium in the presence or absence of agent, and the cumulative number of CCs per dish with time was calculated.
Calculation of kinetic parameters for cumulative clonogenic cells. The cumulative number of CCs from the start of liquid suspension culture was serially plotted on semilogarithmic graphs. Linear regression analysis using SPSS software (IBM, Tokyo, Japan) was performed. The line of the fitted equation describing the plots and the significance of linearity were determined (31). The relative slope of the line (SLP) (rSLP) defined as the ratio of SLP $\mathrm{agent}_{\mathrm{SLP}} / \mathrm{Sontrol}_{\text {cin }}$ reflects the level of SR under treatment by the agent. SR inhibition was defined as a value of rSLP at 0.9 or below (29). Synergistic inhibition of the cumulative number of CCs by a combination of two agents was defined as significant inhibition of the cumulative number of $\mathrm{CCs}$ by simultaneous addition of the two agents compared with that by either one alone. Synergistic inhibition of SR capacity by two agents was defined as that of the cumulative number of CCs at four points or more out of a total of eight points during 4 weeks $(\geq 50 \%)$.

Clonogenic assay in methylcellulose culture. BCF was performed as previously reported (32). Synergistic inhibition of BCF by two agents was defined as significant inhibition of BCF by simultaneous addition of the two agents compared with that by either one alone.

Detection of autophagic vacuoles using monodansylcadaverine $(M D C)$. Autophagic vacuoles were detected by incubating cells with MDC solution (1:1,000 in Cell-Based Assay Buffer, $50 \mu \mathrm{M})$ using an Autophagy/Cytotoxicity Dual Staining Kit (Cayman Chemical Co.). Cells were incubated with MDC for $10 \mathrm{~min}$ at $37^{\circ} \mathrm{C}$, washed three times with PBS and immediately analyzed under a fluorescence Nikon ECLIPSE E600 microscope (Nikon, Tokyo, Japan) equipped with a filter system (excitation wavelength of $365 \mathrm{~nm}$, emission wavelength of $400 \mathrm{~nm}$ ). For quantification of MDC-positive staining of cells, bright-field and fluorescence images were merged, 100 cells were counted in three separate fields by using a fluorescence microscope and the proportion of MDC-positive cells was determined. Images were captured with a Nikon DIGITAL SIGHT DS-Ri1 microscope camera (Nikon) and imported into Photoshop.

Senescence-associated (SA) $\beta$-galactosidase labeling. SA- $\beta$ galactosidase was detected by using Senescence Detection Kit (BioVision Inc., CA, Milpitas, USA). Briefly, cells were fixed for 15 min with Fixative Solution, then washed once with PBS. Cells were then incubated overnight at $37^{\circ} \mathrm{C}$ with Staining Solution Mix containing $1 \mathrm{mg} / \mathrm{ml} \mathrm{X-Gal}$. For SA- $\beta$-gal-positive staining cell quantification, 100 cells were counted in three separate fields by using an inverted microscope (Nikon) and the proportion of SA- $\beta$ galactosidase-positive cells was determined.

Apoptotic cell fraction. Propidium iodide (PI) staining of DNA in permeabilized cells by cell phase determination kit (Cayman Chemical Co.) and its detection by flow cytometry (BD FACSCanto ${ }^{\mathrm{TM}} \mathrm{II}$; BD Biosciences, Tokyo, Japan) were used to identify the hypodiploid cells as the apoptotic cell fraction (33). Fluorescence of PI-stained cells was measured within $30 \mathrm{~min}$ on a FACSCanto $^{\mathrm{TM}}$ II equipped with a doublet discrimination module for $10^{4}$ nuclei.

Trypan blue staining for necrosis. Since loss of membrane integrity is a pathognomonic feature of necrotic cell death, necrotic cells stain with specific membrane-impermeable nucleic acid dyes such as TB in contrast to viable cells (34). A mixture of equal volumes of $0.4 \%$ TB solution in $0.85 \%$ saline and cell suspension was kept for 5 min at room temperature, and cells stained blue were counted as 
positive. For quantification of TB-positively stained cells, 100 cells were counted in three separate fields using an inverted microscope (Nikon) and the proportion of TB-positive cells was determined.

Enhancement and reduction in cellular stress responses, such as autophagy, apoptosis, necrosis and senescence. Enhancement in cellular stress response rate was defined as $\geq 200 \%$ of the control value and $\geq 5 \%$ in value (29). Similarly, reduction in cellular stress response rate was defined as $<50 \%$ of the control value and $\geq 2.5 \%$ in value.

Statistical analyses. Data for BCF are shown as the mean $\pm \mathrm{SD}$ of five replicate cultures. The other assay determinations were carried out in triplicate. The statistical significance was evaluated using Student's $t$-test (two-tailed) and chi-square tests.

\section{Results}

Growth regulation in methylcellulose. Chloroquine inhibited $\mathrm{BCF}$ in a dose-dependent manner, with an $\mathrm{IC}_{50}$ concentration of $14.0,8.3,11.6,10.0,10.6,8.7$ and $9.0 \mu \mathrm{M}$ for HL-60, K562, Mo7e, Daudi, Raji, U-266 and U-937 cell lines, respectively, with a mean $\pm \mathrm{SD}$ of $10.3 \pm 2.0 \mu \mathrm{M}$ (data not shown). Chloroquine, vitamin C, resveratrol, NS-398 and Ind at final concentrations of $3,300,10,30$ and $30 \mu \mathrm{M}$ inhibited BCF by $16 \pm 17 \%, 25 \pm 18 \%, 16 \pm 8 \%, 9 \pm 15 \%$ and $25 \pm 16 \%$ (mean \pm SD of percentage inhibition of control in seven cell lines), respectively (Figure 1). Consequently, the inhibitory effect on BCF was greater in the order of vitamin C, Ind, resveratrol, chloroquine and NS-398, although there was no significant difference between the effect of the five agents. Thus, the final concentrations of agents used were less than the $\mathrm{IC}_{50} \mathrm{~s}$ except in two conditions (K-562 with vitamin $\mathrm{C}$ or Ind).

Inhibition of BCF. Chloroquine, vitamin $\mathrm{C}$, resveratrol, NS398 and Ind significantly inhibited BCF in five (71\%), six $(86 \%)$, four $(57 \%)$, five $(71 \%)$ and six $(86 \%)$ out of seven cell lines, respectively, under a total of 26 out of 35 conditions (74\%) (Figure 1).

Synergistic inhibition of BCF by chloroquine and another agent. Chloroquine in combination with vitamin $\mathrm{C}$, resveratrol, NS-398 and Ind synergistically inhibited BCF in one $(14 \%)$, two $(29 \%)$, none $(0 \%)$ and one $(14 \%)$ out of seven cell lines, respectively, under a total of four out of 28 conditions (14\%) (Figure 1).

Growth regulation in liquid suspension. A significant logarithmic linear increase in the cumulative number of CCs recovered per dish for up to 4 weeks was noted under all of the 70 conditions with or without the agents $[p<0.01$; $\mathrm{r}=0.993 \pm 0.007$ (range $=0.973-0.999)$ ] (Figures 2-5).

Synergistic inhibition of blast progenitor SR by chloroquine and phytochemicals. Chloroquine and vitamin $\mathrm{C}$ synergistically inhibited SR in four cell lines (HL-60, K-562,
Daudi and U-937) (57\%) (Figure 2). Chloroquine and resveratrol synergistically inhibited SR in all seven cell lines except one (U-266; 86\%) (Figure 3). Chloroquine, vitamin $\mathrm{C}$ and a combination of chloroquine with resveratrol reduced the rSLP level to almost zero in U-266, Daudi and Raji cells at day 30, 30 and 25, respectively. In contrast, in Raji cells, chloroquine combined with vitamin $\mathrm{C}$ almost completely abolished the reduction in rSLP level induced by vitamin $\mathrm{C}$ and chloroquine alone. In U-266 cells, vitamin $\mathrm{C}$ or resveratrol partially abolished the reduction in rSLP level by chloroquine at day 30 .

Synergistic inhibition of blast progenitor self-renewal by chloroquine and nonsteroidal anti-inflammatory drugs. Chloroquine and NS-398 synergistically inhibited SR in Daudi cells alone (14\%) (Figure 4). In contrast, NS-398 abolished the reduction in rSLP level by chloroquine in U266 cells at day 30. Chloroquine and Ind synergistically inhibited SR in all seven cell lines except in two (Raji and U-266; 71\%) (Figure 5).

Thus, chloroquine in combination with phytochemicals or NSAIDs synergistically inhibited SR under a total of 16 out of 28 conditions $(57 \%)$. There was no significant correlation between BCF (relative to the control) and rSLP level $(n=63$; $\mathrm{r}=0.264, \mathrm{t}=2.136, p>0.05$ ) (Figures 1-5).

Changes in cellular stress responses in liquid suspension. Autophagic, apoptotic, necrotic and senescent cell rates were serially determined. Representative Daudi cells with autophagic vacuoles are shown in Figure 6. In HL-60 cells, all four types of stress response reached a peak at day 4 or 7 except for necrosis by vitamin $\mathrm{C}$ or Ind (Figure 7A). In K562 cells, autophagy and senescence reached a peak at day 4, whereas apoptosis and necrosis reached a peak at day 7 , except for apoptosis by resveratrol or Ind with a peak at day 4. In Mo7e cells, apoptosis and necrosis reached a peak at day 4 except for necrosis by resveratrol with a peak at day 10 , whereas autophagy and senescence reached a peak at day 7 or 10. In Daudi cells, autophagy, apoptosis and senescence reached a peak at day 4 or 7 except for autophagy by NS398 with a peak at day 10 , whereas necrosis reached a peak at day 10 (Figure 7B). In Raji cells, autophagy, apoptosis and necrosis reached a peak at day 4 except for necrosis by NS398 or Ind with a peak at day 7. In U-266 and U-937 cells, all four types of stress response reached a peak at day 4 or 7 except for senescence by vitamin $\mathrm{C}$ and apoptosis and necrosis by resveratrol or Ind, respectively.

Cellular stress response and SR capacity. Under 11 conditions (K-562 cells with resveratrol or Ind, Mo7e cells with resveratrol, Daudi cells with vitamin C, resveratrol or Ind, Raji cells with resveratrol, U-266 cells with vitamin C, resveratrol or NS-398 and U-937 cells with resveratrol) leading to enhanced apoptosis, necrosis or senescence, SR 


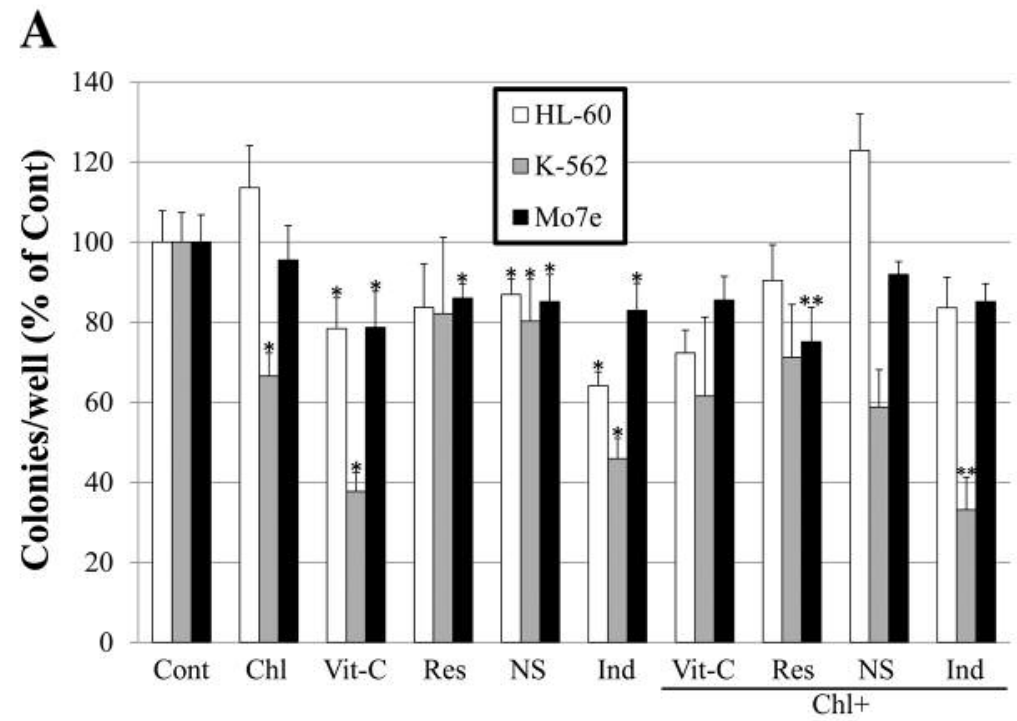

\section{B}

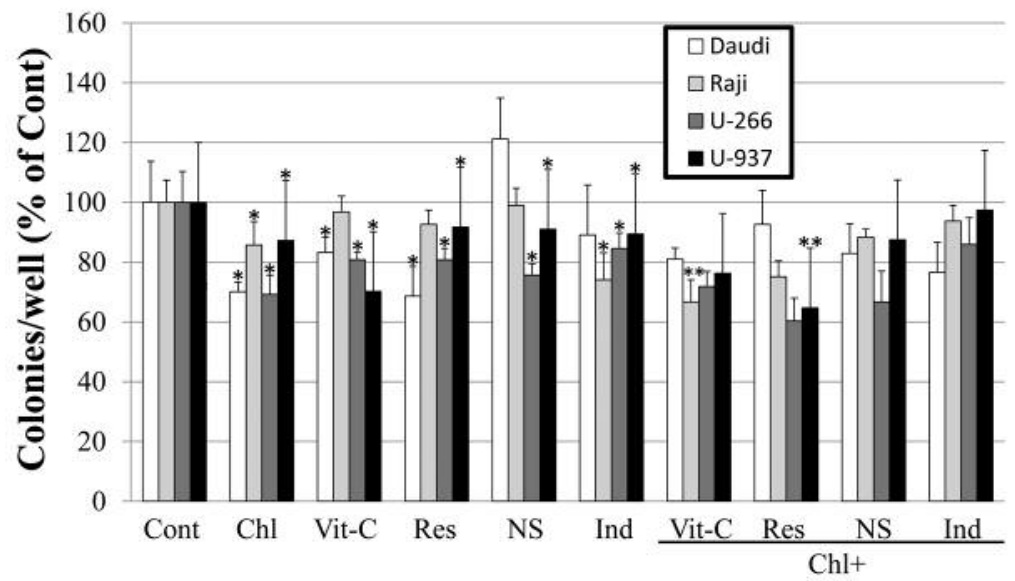

Figure 1. Effects of chloroquine (Chl), phytochemicals, nonsteroidal anti-inflammatory drugs and a combination of chloroquine with other agents on blast colony formation (BCF) in HL-60, K-562, Mo7e, Daudi, Raji, U-266 and U-937 cells. Myeloid (A) and lymphoid (B) cells were treated in methylcellulose with $0.38 \%$ dimethyl sulfoxide (DMSO) alone (control, Cont) or with DMSO plus vitamin C (Vit-C), resveratrol (Res), cyclo-oxygenase inhibitor NS-398 (NS) or indomethacin heptyl ester (Ind) in the presence or absence of $3 \mu M$ chloroquine. The number of blast colonies per well in

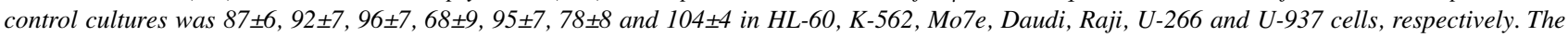
data shown represent the mean $\pm S D$ of five replicate cultures. The data were normalized as the percentage of the control value in each experiment. *Significantly different at $p<0.05$ when compared with control cultures. **Synergistic inhibition of BCF by chloroquine with another agent.

inhibition and synergistic inhibition of SR with chloroquine were absent in U-266 cells treated with NS-398 and U-266 cells treated with vitamin C, resveratrol or NS-398, respectively (Figures 2-5). Under the remaining 17 conditions with none of these enhanced stress responses, SR inhibition and synergistic inhibition of SR with chloroquine were observed in Raji cells with vitamin $\mathrm{C}$ and U-937 cells with NS-398; and HL-60 cells with vitamin C, resveratrol or Ind, K-562 cells with vitamin C, Mo7e cells with Ind, Daudi cells with NS-398 and U-937 cells with vitamin $\mathrm{C}$ or Ind, respectively. Between the two groups, the frequency of $\mathrm{SR}$ inhibition was significantly different $\left(10 / 11\right.$ vs. $\left.2 / 17, \chi^{2}=17.093, p<0.01\right)$, whereas that of synergistic inhibition of SR with chloroquine was not significantly different $\left(8 / 11\right.$ vs. $\left.8 / 17, \chi^{2}=1.79, p>0.05\right)$. Furthermore, the frequency of SR inhibition was also still significantly high under 10 conditions with enhanced apoptosis or necrosis compared with remaining 18 conditions with neither apoptotic nor necrotic enhancement $\left(9 / 10\right.$ vs. $\left.3 / 18, \chi^{2}=14.106, p<0.01\right)$. Conversely, reduction 

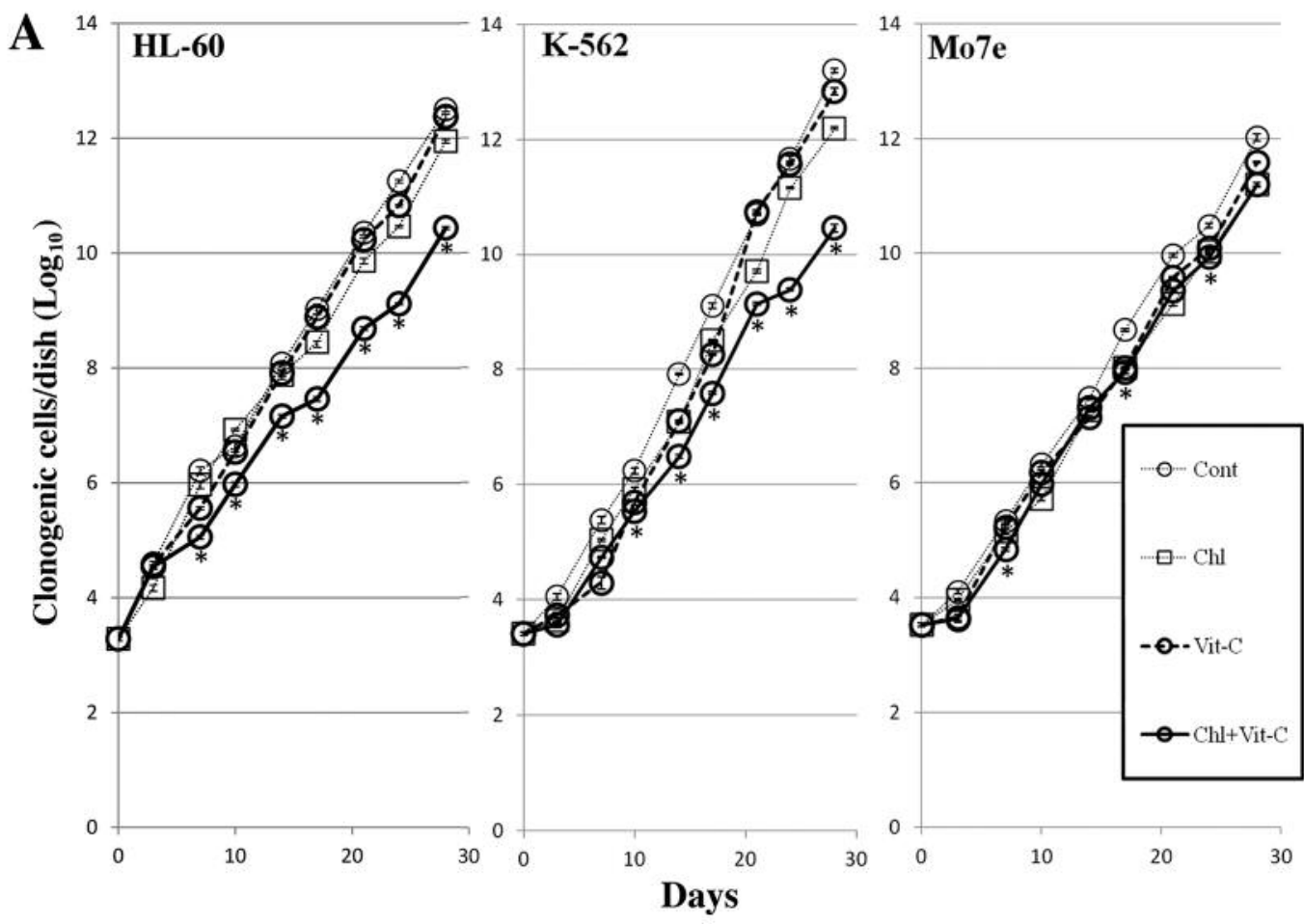

B

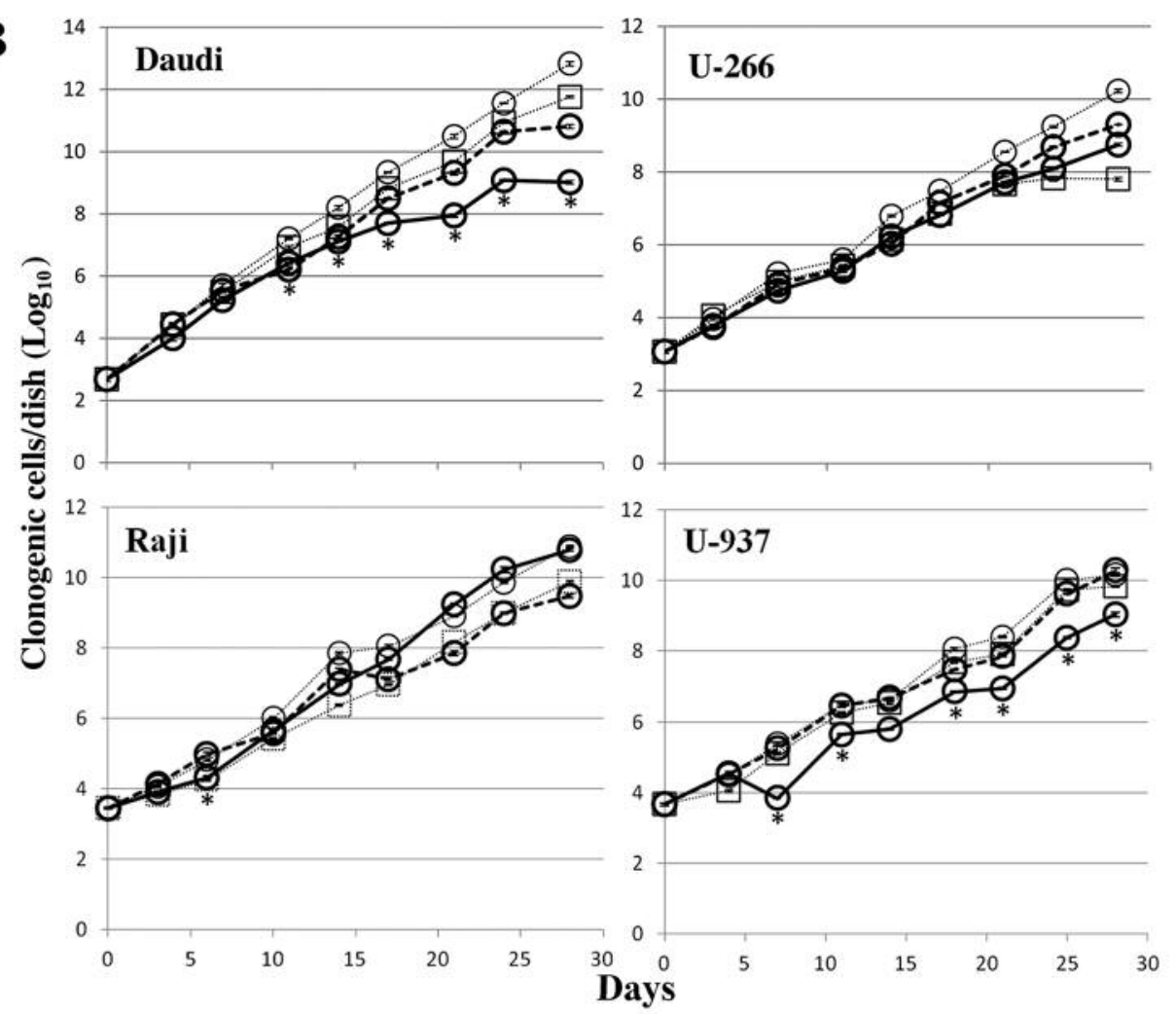

Figure 2. Synergistic inhibition of blast clonogenic self-renewal by chloroquine (Chl) and vitamin C (Vit-C) in HL-60, K-562, Mo7e, Daudi, Raji, U-266 and U-937 cells. Myeloid (A) and lymphoid (B) cells were cultured in suspension with $0.38 \%$ dimethyl sulfoxide (DMSO) alone (control, Cont) or with DMSO plus $300 \mu \mathrm{M}$ vitamin $C$ in the presence or absence of $3 \mu \mathrm{M}$ chloroquine and cumulative clonogenic cell recovery was determined in long-term suspension cultures. The data shown represent the mean $\pm S D$ of five replicate cultures. Both chloroquine and vitamin $C$ alone inhibited selfrenewal in three cell lines (Daudi, Raji and U-266). *Synergistic inhibition of cumulative number of clonogenic cells by chloroquine and vitamin $C$. 

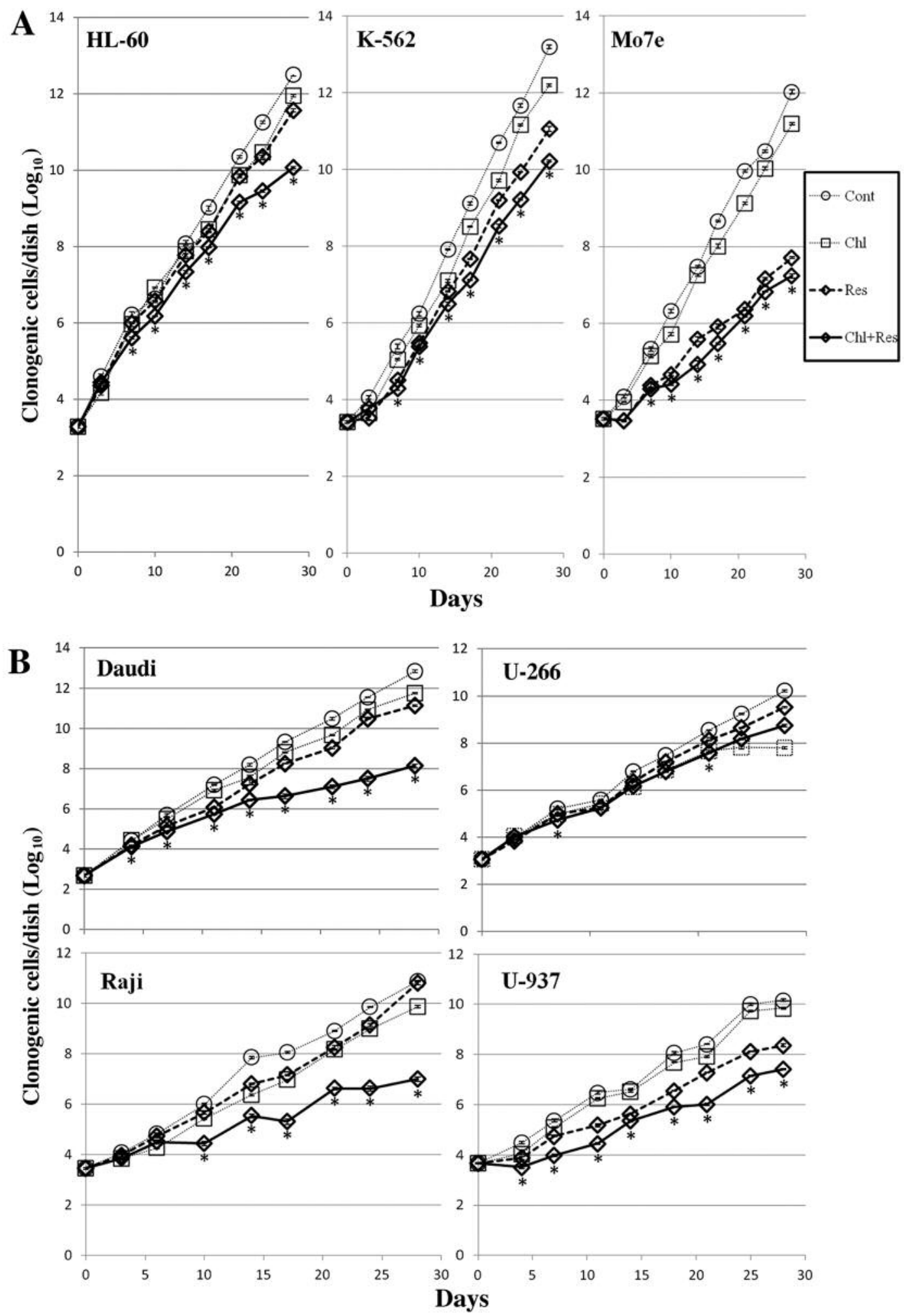

Figure 3. Synergistic inhibition of blast clonogenic self-renewal by chloroquine (Chl) and resveratrol (Res) in HL-60, K-562, Mo7e, Daudi, Raji, U266 and U-937 cells. Myeloid (A) and lymphoid (B) cells were cultured in suspension with $0.38 \%$ dimethyl sulfoxide (DMSO) alone (control, Cont) or with DMSO plus $10 \mu \mathrm{M}$ resveratrol in the presence or absence of $3 \mu \mathrm{M}$ chloroquine and cumulative clonogenic cell recovery was determined in longterm suspension cultures. The data shown represent the mean $\pm S D$ of five replicate cultures. Resveratrol alone inhibited self-renewal in six (K-562, Mo7e, Daudi, Raji, U-266 and U-937) cell lines. *Synergistic inhibition of cumulative number of clonogenic cells by chloroquine and resveratrol. 

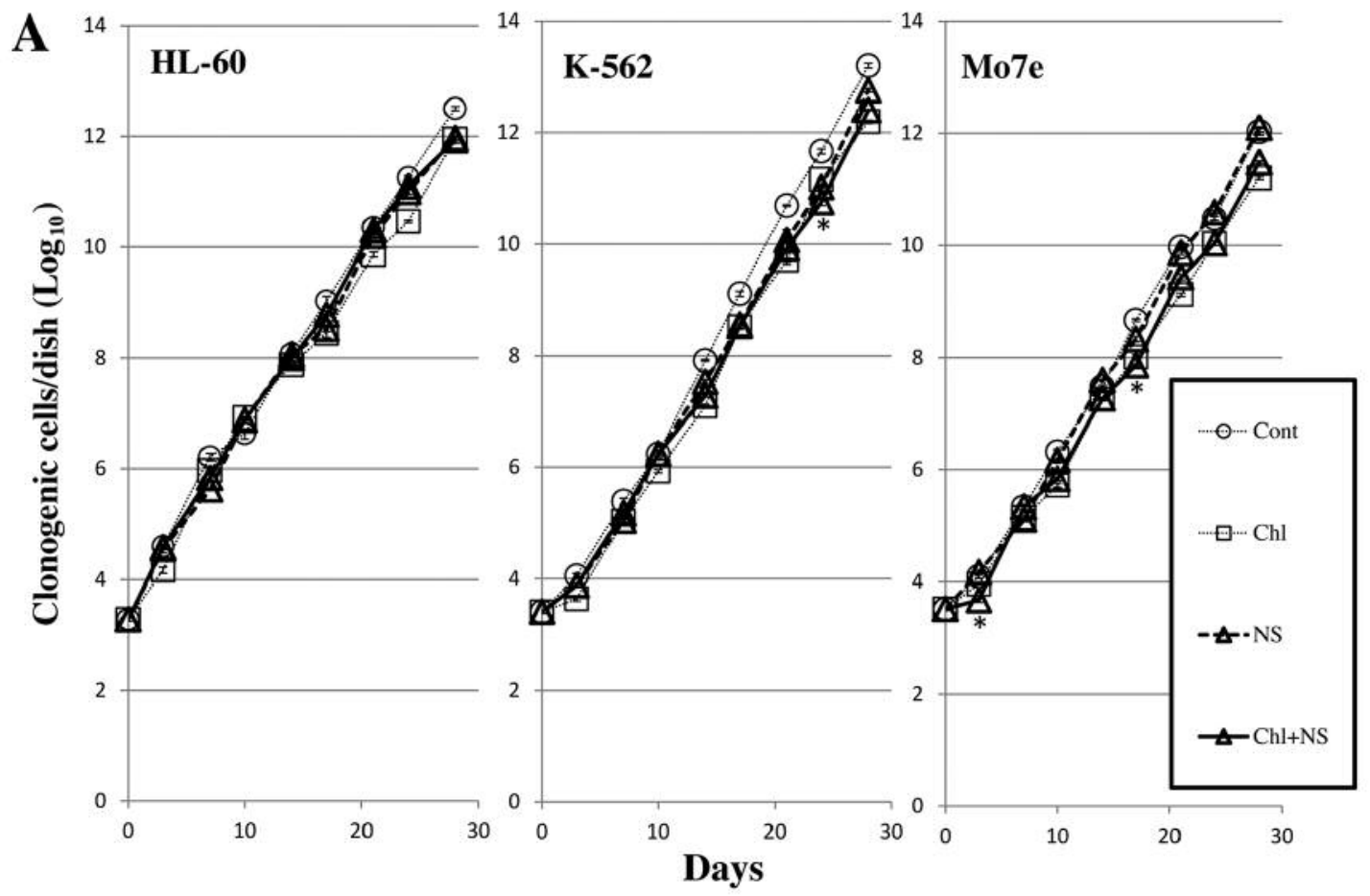

\section{B}

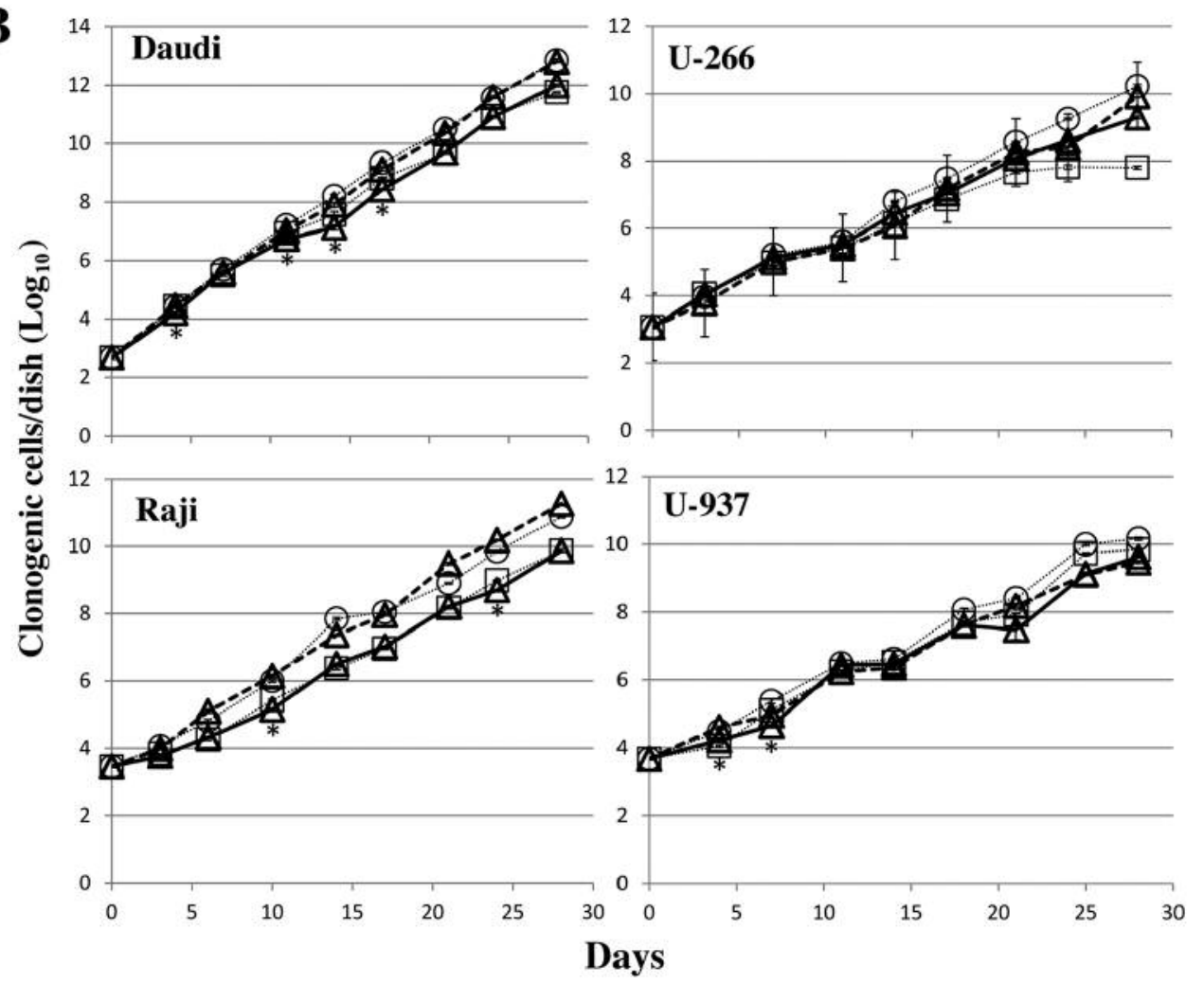

Figure 4. Synergistic inhibition of blast clonogenic self-renewal by chloroquine (Chl) and cyclo-oxygenase inhibitor NS-398 (NS) in HL-60, K-562, Mo7e, Daudi, Raji, U-266 and U-937 cells. Myeloid (A) and lymphoid (B) cells were cultured in suspension with 0.38\% dimethyl sulfoxide (DMSO) alone (control, Cont) or with DMSO plus $30 \mu M N S-398$ in the presence or absence of $3 \mu M$ chloroquine and cumulative clonogenic cell recovery was determined in long-term suspension cultures. The data shown represent the mean $\pm S D$ of five replicate cultures. NS alone inhibited self-renewal in one cell line (Daudi). *Synergistic inhibition of cumulative number of clonogenic cells by chloroquine and NS-398. 

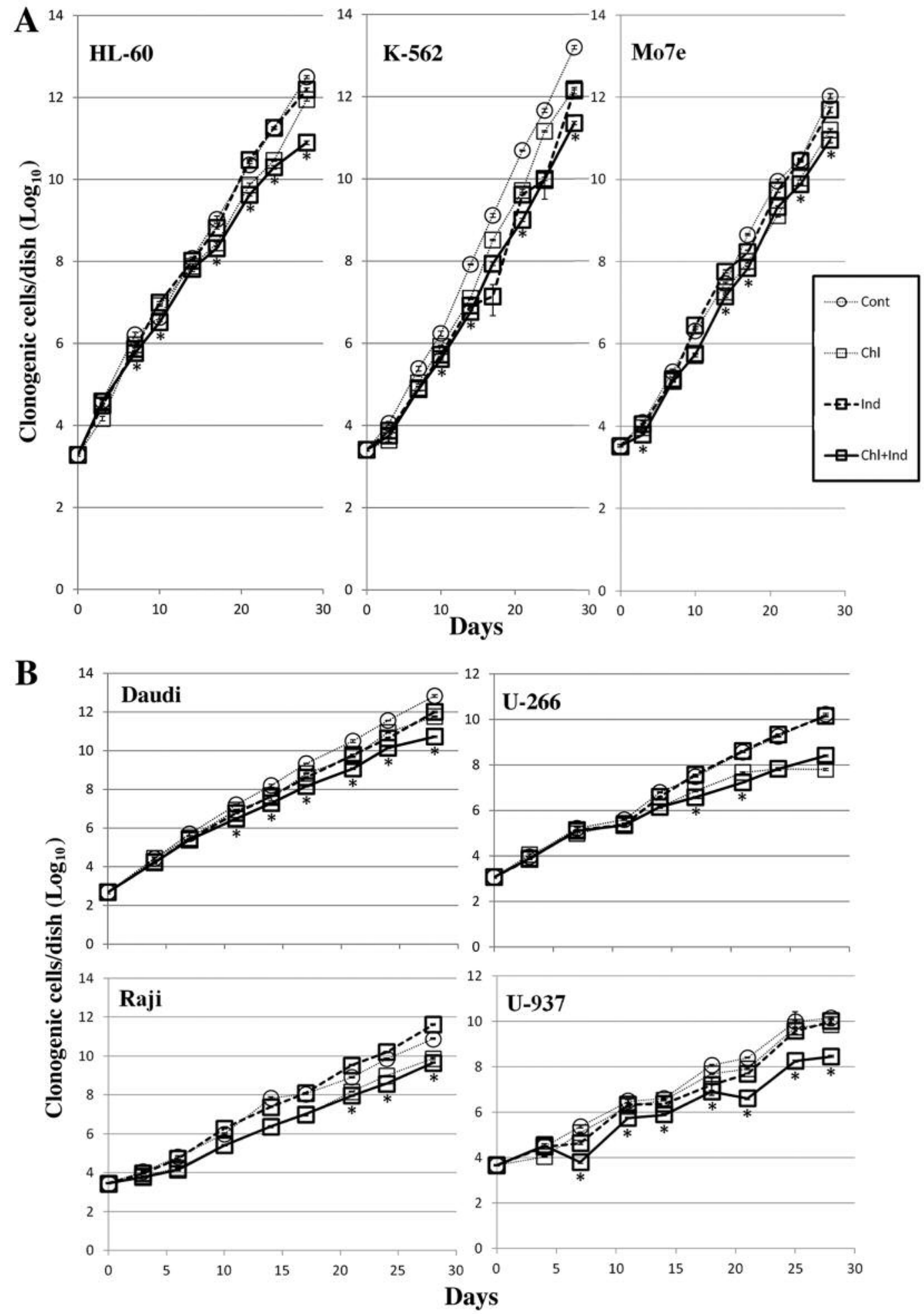

Figure 5. Synergistic inhibition of blast clonogenic self-renewal by chloroquine (Chl) and indomethacin heptyl ester (Ind) in HL-60, K-562, Mo7e, Daudi, Raji, U-266 and U-937 cells. Myeloid (A) and lymphoid (B) cells were cultured in suspension with 0.38\% dimethyl sulfoxide (DMSO) alone (control, Cont) or with DMSO plus $30 \mu \mathrm{M}$ indomethacin heptyl ester in the presence or absence of $3 \mu \mathrm{M}$ chloroquine and cumulative clonogenic cell recovery was determined in long-term suspension cultures. The data shown represent the mean $\pm S D$ of five replicate cultures. Indomethacin heptyl ester alone inhibited self-renewal in two cell lines (K-562 and Daudi). *Synergistic inhibition of cumulative number of clonogenic cells by chloroquine and indomethacin heptyl ester. 

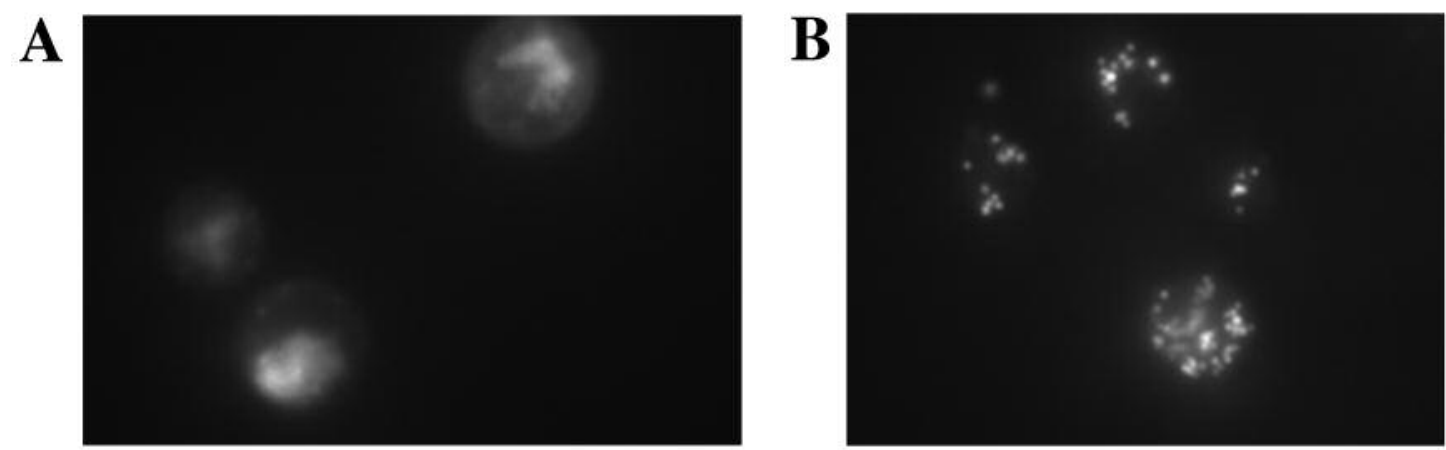

Figure 6. Resveratrol (Res) increases autophagy in Daudi cells as shown by fluorescence microscopy. Daudi cells were cultured in suspension with $0.38 \%$ dimethyl sulfoxide (DMSO) alone (A) or with $10 \mu \mathrm{M}$ resveratrol (B). After 4 days, cells were stained with monodansylcadaverine staining solution and images were captured with a Nikon DIGITAL SIGHT DS-Ril microscope camera at 400x magnification.

of apoptosis (Mo7e and U-266 cells with Ind) or necrosis (HL-60 cells with Ind and HL-60, K-562, Mo7e and Raji cells with NS-398) resulted in lack of SR inhibition, but not necessarily synergistic inhibition of SR with chloroquine (HL-60 and Mo7e cells with Ind).

Neither SR inhibition $\left(9 / 23\right.$ vs. $\left.3 / 5, \chi^{2}=0.739, p>0.05\right)$ nor synergistic inhibition of SR with chloroquine (12/23 vs. 4/5, $\left.\chi^{2}=1.289, p>0.05\right)$ significantly correlated with enhanced autophagy.

\section{Discussion}

As previously reported $(13-15,18,19)$, in the present study we demonstrated that phytochemicals and NSAIDs enhanced not only apoptosis, necrosis and senescence but also autophagy in seven malignant hematological cell lines. Thus, it might be assumed that chloroquine in combination with phytochemicals or NSAIDs effectively inhibits malignant cell growth (9-19). Accordingly, a combination of chloroquine and another agent synergistically inhibited SR in liquid suspension $(16 / 28,57 \%)$ more frequently than it did BCF in methylcellulose $(4 / 28,14 \%$ ) (McNemar's test, $\left.\chi^{2}=10.286, p<0.01\right)$. This may be partly explained by longterm exposure of the cells to the agents in liquid suspension and increased dependence of immature stem cell survival on autophagic activity compared with mature cells (8, 27-29, $35)$. Continuous exposure to resveratrol and induction of cellular stress responses have been revealed to be necessary to inhibit stem cell SR $(8,28)$.

We also demonstrated that phytochemicals and NSAIDs induce coincident elevation of apoptosis and necrosis and of senescence and autophagy. Namely, induction of apoptosis and necrosis preceded, coincided with or succeeded that of autophagy and senescence. In Daudi cells, however, induction of necrosis succeeded that of the other three types of stress response.
Apoptosis is classified as programmed cell death I, characterized by morphological features such as rounding up of the cell and caspase activation (36). Necrosis is usually considered to be uncontrolled and accidental. However, recent research suggests that its occurrence and course might be tightly regulated (37).

Senescence is characterized by irreversible cell-cycle arrest (38-40), overexpression of cyclin-dependent kinase inhibitors, caspase-independent cell death and a strong resistance to apoptosis (41). Exogenous expression of p53 in senescent cells restored their ability to undergo p53dependent apoptosis, suggesting that apoptosis resistance in senescent cells may be mediated by changes in p53 signaling (42). Autophagy also blocks the induction of apoptosis and, if apoptotic response starts, autophagy can be inhibited, in part due to the caspase-mediated cleavage of essential autophagy proteins (43).

In contrast, senescence and autophagy exist as parallel processes, and the inhibition of autophagy delays the senescence process $(44,45)$. Recent literature highlights the intricate interplay between apoptosis, necrosis and autophagy in normal development and in pathology $(46,47)$. It is also reported that the senescence response was potentiated by apoptosis inhibition in an autophagy-dependent way (48).

It has been reported that cellular senescence plausibly contributes to therapy resistance $(49,50)$. We observed, in the present study, that induction of apoptosis or necrosis, but not necessarily that of senescence, results in inhibition of SR. Alternatively, as we have partly reported previously (29), reduction of apoptosis or necrosis resulted in lack of SR inhibition.

In the present study, we showed that chloroquine, vitamin C, resveratrol and NS-398 abolished the inhibition of SR by another agent in four out of 28 conditions (14\%). Autophagy can either result in chemoresistance $(9,10)$ or induce autophagic cell death $(8,15,51-53)$. 

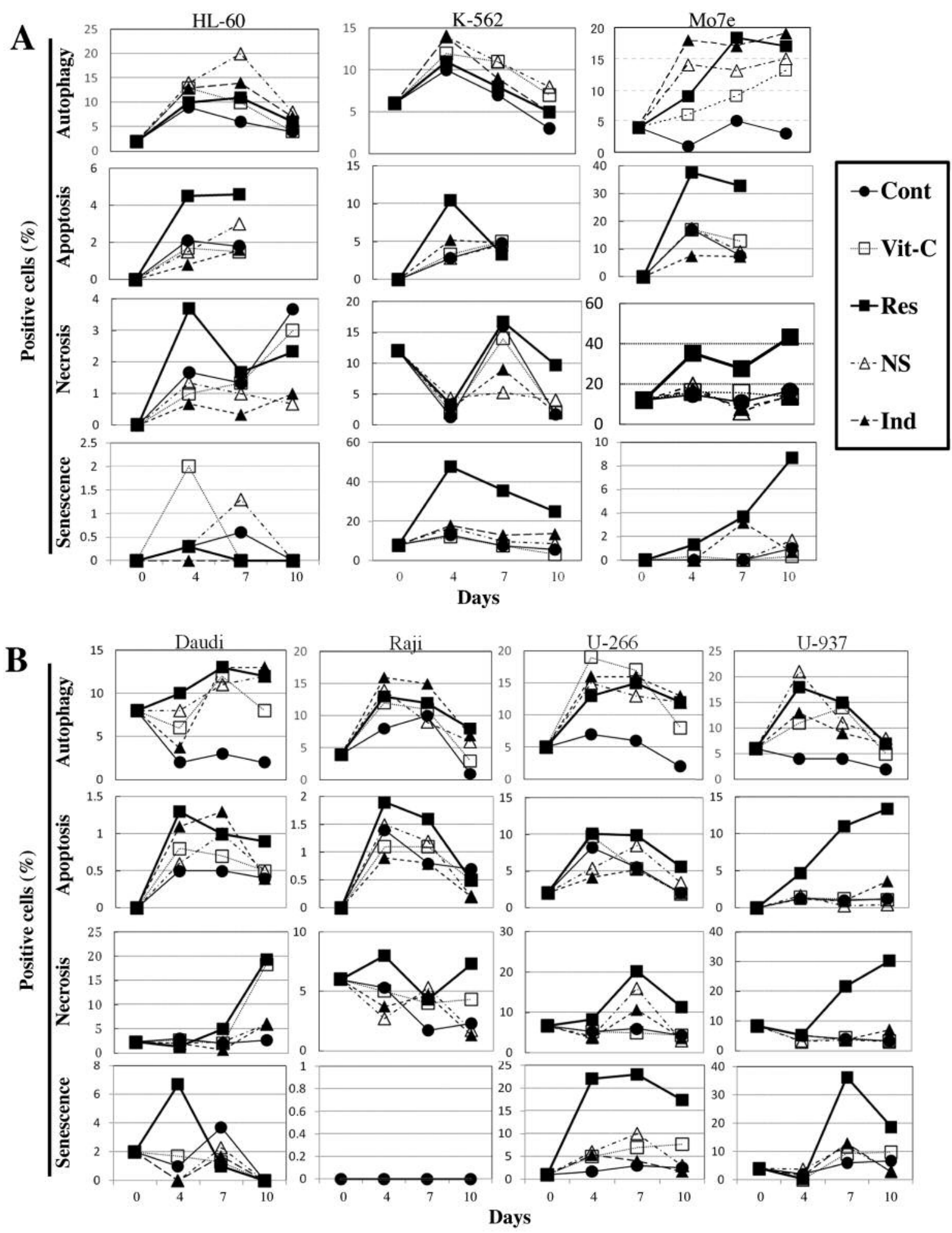

Figure 7. Cellular stress responses in liquid suspension cultures of HL-60, K-562, Mo7e, Daudi, Raji, U-266 and U-937 cells. Myeloid (A) and lymphoid (B) cells were treated in suspension with $0.38 \%$ dimethyl sulfoxide (DMSO) alone (control, Cont) or DMSO plus $300 \mu \mathrm{M}$ vitamin C (VitC), $10 \mu \mathrm{M}$ resveratrol (Res), $30 \mu \mathrm{M}$ cyclo-oxygenase inhibitor NS-398 (NS) or $30 \mu \mathrm{M}$ indomethacin heptyl ester (Ind). The percentage of cells stained with monodansylcadaverine (autophagy), propidium iodide (apoptosis), trypan blue (necrosis) or $\beta$-galactosidase (senescence) was determined. The data shown represent the mean of three separate measurements. 
In contrast to $\mathrm{SR}$ regulation, regulation of apoptosis and necrosis was not significantly correlated with synergistic regulation of SR. Further studies are required to uncover the complex interactions between autophagy and other three types of cellular stress responses in synergistic regulation of SR capacity in hematological malignant cells, including synergistic regulation of apoptosis or necrosis using a combination of chloroquine and another agent (54).

\section{Conflicts of Interest}

The Authors declare no conflict of interest in regard to this study.

\section{Acknowledgements}

The Authors are indebted Drs. Susumu Ohshima and Masami Bessho (Saitama Medical University, Saitama) for discussion of flow cytometric data and Drs. Ryo Kubota and Katsumi Ando (Saitama Prefectural University) for statistical analysis. This work was supported by a 2016 Grant-in-Aid encouragement of Scientists Research Funds, Saitama Prefectural University.

\section{References}

1 Khuda-Bukhsh AR, Das S and Saha SK: Molecular approaches toward targeted cancer prevention with some food plants and their products: Inflammatory and other signal pathways. Nutr Cancer 66: 194-205, 2014.

2 Carter LG, D'Orazio JA and Pearson KJ: Resveratrol and cancer: Focus on in vivo evidence. Endocr Relat Cancer 21: R209-225, 2014.

3 Ohno S, Ohno Y, Suzuki N, Soma G and Inoue M: High-dose vitamin $\mathrm{C}$ (ascorbic acid) therapy in the treatment of patients with advanced cancer. Anticancer Res 29: 809-815, 2009.

4 Kawada H, Kaneko M, Sawanobori M, Uno T, Matsuzawa H, Nakamura Y, Matsushita $\mathrm{H}$ and Ando K: High concentrations of L-ascorbic acid specifically inhibit the growth of human leukemic cells via down-regulation of HIF-1 $\alpha$ transcription. PLoS One 8: e62717, 2013.

5 Rothwell PM, Wilson M, Elwin CE, Norrving B, Algra A, Warlow CP and Meade TW: Long-term effect of aspirin on colorectal cancer incidence and mortality: 20-year follow-up of five randomized trials. Lancet 376: 1741-1750, 2010.

6 Liggett JL, Zhang X, Eling TE and Baek SJ: Anti-tumor activity of non-steroidal anti-inflammatory drugs: cyclooxygenaseindependent targets. Cancer Lett 346: 217-224, 2014.

7 Rothwell PM, Cook NR, Gaziano JM, Price JF, Belch JFF, Roncaglioni MC, Morimoto T and Mehta Z: Effects of aspirin on risks of vascular events and cancer according to body weight and dose: analysis of individual patient data from randomised trials. Lancet 392: 387-399, 2018.

8 Peltz L, Gomez J, Marquez M, Alencastro F, Atashpanjeh N, Quang T, Bach T and Zhao Y: Resveratrol exerts dosage and duration dependent effect on human mesenchymal stem cell development. PLoS One 7: e37162, 2012.

9 Altman JK, Szilard A, Goussetis DJ, Sassano A, Colamonici M, Gounaris E, Frankfurt O, Giles FJ, Eklund EA, Beauchamp EM and Platanias LC: Autophagy is a survival mechanism of acute myeloid leukemia precursors during dual mTORC2/mTORC1 targeting. Clin Cancer Res 20: 2400-2409, 2014.

10 Kenific CM and Debnath J: Cellular and metabolic functions for autophagy in cancer cells. Trends Cell Biol 25: 37-45, 2015.

$11 \mathrm{Su} \mathrm{M}$, Chao G, Liang M, Song J and Wu K: Anticytoproliferative effect of vitamin $\mathrm{C}$ on rat hepatic stellate cell. Am J Transl Res 8: 2820-2825, 2016.

12 Ma Y, Chapman J, Levine M, Polireddy K, Drisko J and Chen Q: High-dose parenteral ascorbate enhanced chemosensitivity of ovarian cancer and reduced toxicity of chemotherapy. Sci Transl Med 6: 222ra18, 2014.

13 Din FV, Valanciute A, Houde VP, Zibrova D, Green KA, Sakamoto K, Alessi DR and Dunlop MG: Aspirin inhibits mTOR signaling, activates AMP-activated protein kinase, and induces autophagy in colorectal cancer. Gastroenterology 142: 15041515, 2012.

14 Henry WS, Laszewski T, Tsang T, Beca F, Beck AH, McAllister SS and Toker A: Aspirin suppresses growth in PI3K-mutated breast cancer by activating AMPK and inhibiting mTORC1 signaling. Cancer Res 77: 790-801, 2017.

15 Park D, Jeong H, Lee MN, Koh A, Kwon O, Yang YR, Noh J, Suh PG, Park H and Ryu SH: Resveratrol induces autophagy by directly inhibiting mTOR through ATP competition. Sci Rep 6: 21772, 2016.

16 Zhang YJ, Bao YJ, Dai Q, Yang WY, Cheng P, Zhu LM, Wang $\mathrm{BJ}$ and Jiang FH: mTOR signaling is involved in indomethacin and nimesulide suppression of colorectal cancer cell growth via a COX-2 independent pathway. Ann Surg Oncol 18: 580-588, 2011.

17 Pantovic A, Bosnjak M, Arsikin K, Kosic M, Mandic M, Ristic B, Tosic J, Grujicic D, Isakovic A, Micic N, Trajkovic V and Harhaji-Trajkovic L: In vitro antiglioma action of indomethacin is mediated via AMP-activated protein kinase/mTOR complex 1 signalling pathway. Int J Biochem Cell Biol 83: 84-96, 2017.

18 Fukui M, Yamabe N, Choi HJ, Polireddy K, Chen Q and Zhu BT: Mechanism of ascorbate-induced cell death in human pancreatic cancer cells: role of Bcl-2, Beclin 1 and autophagy. Planta Med 81: 838-46, 2015.

19 Harada S, Nakagawa T, Yokoe S, Edogawa S, Takeuchi T, Inoue T, Higuchi K and Asahi M: Autophagy deficiency diminishes indomethacin-induced intestinal epithelial cell damage through activation of the ERK/Nrf2/HO-1 pathway. J Pharmacol Exp Ther 355: 353-361, 2015.

20 Goardon N, Marchi E, Atzberger A, Quek L, Schuh A, Soneji S, Woll P, Mead A, Alford KA, Rout R, Chaudhury S, Gilkes A, Knapper S, Beldjord K, Begum S, Rose S, Geddes N, Griffiths M, Standen G, Sternberg A, Cavenagh J, Hunter H, Bowen D, Killick S, Robinson L, Price A, Macintyre E, Virgo P, Burnett A, Craddock C, Enver T, Jacobsen SE, Porcher C and Vyas P: Coexistence of LMPP-like and GMP-like leukemia stem cells in acute myeloid leukemia. Cancer Cell 19: 138-152, 2011.

21 Castor A, Nilsson L, Astrand-Grundström I, Buitenhuis M, Ramirez C, Anderson K, Strömbeck B, Garwicz S, Békássy AN, Schmiegelow K, Lausen B, Hokland P, Lehmann S, Juliusson G, Johansson B and Jacobsen SE: Distinct patterns of hematopoietic stem cell involvement in acute lymphoblastic leukemia. Nat Med 11: 630-637, 2005.

22 Nara $\mathrm{N}$ and McCulloch EA: The proliferation in suspension of the progenitors of the blast cells in acute myeloblastic leukemia. Blood 65: 1484-1493, 1985. 
23 Minden MD, Buick RN and McCulloch EA: Separation of blast cell and T-lymphocyte progenitors in the blood of patients with acute myeloblastic leukemia. Blood 54: 186-195, 1979.

24 Nara N, Tohda S, Suzuki T, Nagata K, Yamashita Y, Imai Y, Maruyama Y and Tomiyama J: Effects of N4-Behenoyl-1- $\beta-D-$ Arabinofuranosylcytosine on blast progenitors of acute myeloblastic leukemia. Cancer Res 50: 7587-7592, 1990.

25 Nara N, Chen GJ, Murohashi I, Tohda S, Imai Y, Tomiyama J, Nagata K, Suzuki T, Tanikawa $\mathrm{S}$ and Shiina $\mathrm{S}$ : The in vitro growth patterns and drug sensitivities of leukemic blast progenitors among the subtypes of acute myelocytic leukemia Exp Hematol 20: 904-908, 1992.

26 Oguro $\mathrm{H}$ and Iwama A: Life and death in hematopoietic stem cells. Cur Opin Immunol 19: 503-509, 2007.

27 Folkerts H, Hilgendorf S, Wierenga ATJ, Jaques J, Mulder AB, Coffer PJ, Schuringa JJ and Vellenga E: Inhibition of autophagy as a treatment strategy for p53 wild-type acute myeloid leukemia. Cell Death Dis 8: e2927, 2017.

28 Zhang Y, Zhao Y, Miyahara K, Shimada M, Tanaka KI, Hayashi $\mathrm{H}$, Ihara $\mathrm{N}$ and Murohashi I: Effects of resveratrol and vitamin $\mathrm{C}$ on the self-renewal capacity of blast progenitors in hematologic malignancies. J Leuk S1: 006, 2015.

29 Zhang Y, Zhao Y, Miyahara K, Shimada M, Tanaka KI, Hayashi H, Ihara $\mathrm{N}$ and Murohashi I: Effects of nonsteroidal anti-inflammatory drugs on the self-renewal capacity of blast progenitors in hematological malignancies. Anticancer Res 37: 2315-2322, 2017.

30 Avanzi GC, Lista P, Giovinazzo B, Miniero R, Saglio G, Benetton G, Coda R, Cattoretti G and Pegoraro L: Selective growth response to IL-3 of a human leukaemic cell line with megakaryoblastic features. Br J Haematol 69: 359-66, 1988.

31 Yoshida K, Murohashi I and Hirashima K: p53-independent induction of $\mathrm{p} 21$ (WAF1/CIP1) during differentiation of HL-60 cells by tumor necrosis factor alpha. Int J Hematol 65: 41-48, 1996.

32 Elmore S: Apoptosis: a review of programmed cell death. Toxicol Pathol 35: 495-516, 2007.

33 Murohashi I, Yoshida K, Kishimoto K, Takahashi T, Wakao D, Jinnai I, Yagasaki F, Kawai N, Suzuki T, Matsuda A, Hirashima $\mathrm{K}$ and Bessho M: Differential response to stem cell factor and Flt3 ligand by the FAB subtype in acute myeloid leukemia clonogenic cells. J Interferon Cytokine Res 22: 335-341, 2002.

34 Wakao D, Murohashi I, Tominaga K, Yoshida K, Kishimoto K, Yagasaki F, Itoh Y, Itoh K, Sakata T, Kawai N, Kayano H, Suzuki T, Matsuda A, Hirashima K and Bessho M: Serum thymidine kinase and soluble interleukin-2 receptor predict recurrence of malignant lymphoma. Ann Hematol 81: 140-146, 2002.

35 García-Prat L, Martínez-Vicente M, Perdiguero E, Ortet L, Rodríguez-Ubreva J, Rebollo E, Ruiz-Bonilla V, Gutarra S, Ballestar E, Serrano AL, Sandri M and Muñoz-Cánoves P: Autophagy maintains stemness by preventing senescence. Nature 529: 37-42, 2016.

36 Galluzzi L, Joza N, Tasdemir E, Maiuri MC, Hengartner M, Abrams JM, Tavernarakis N, Penninger J, Madeo F and Kroemer G: No death without life: vital function of apoptotic effectors Cell Death Differ 15: 1113-1123, 2009.

37 Krysko DV, Vanden Berghe T, Parthoens E, D’Herde K and Vandenabeele P: Methods for distinguishing apoptosis from necrotic cells and measuring their clearance. Methods Enzymol 442: 307-341, 2008.
38 Sherwood SW, Rush D, Ellsworth JL and Schimke RT: Defining cellular senescence in IMR-90 cells: a flow cytometric analysis. Proc Natl Acad Sci USA 85: 9086-9090, 1988.

39 Filippi-Chiela EC, Villodre ES, Zamin LL and Lenz G: Autophagy interplay with apoptosis and cell cycle regulation in the growth inhibiting effect of resveratrol in glioma cells. PLoS One 6: e20849, 2011.

40 Wang W: Knockdown of regulator of cullins-1 (ROC1) expression induces bladder cancer cell cycle arrest at the G2 phase and senescence. PLoS One 8: e62734, 2013.

41 Ohtani N, Mann DJ and Hara E: Cellular senescence: its role in tumor suppression and aging. Cancer Sci 100: 792-797, 2009.

42 Seluanov A, Gorbunova V, Falcovitz A, Sigal A, Milyavsky M, Zurer I, Shohat G, Goldfinger N and Rotter V: Change of the death pathway in senescent human fibroblasts in response to DNA damage is caused by an inability to stabilize p53. Mol Cell Biol 21: 1552-1564, 2001.

43 Marino G, Niso-Santano M, Baehrecke EH and Kroemer G: Self-consumption: the interplay of autophagy and apoptosis. Nat Rev Mol Cell Biol 15: 81-94, 2014.

44 Young AR: Autophagy mediates the mitotic senescence transition. Genes Dev 23: 798-803, 2009.

45 Narita M, Young AR, Arakawa S, Samarajiwa SA, Nakashima T, Yoshida S, Hong S, Berry LS, Reichelt S, Ferreira M, Tavaré S, Inoki K, Shimizu S and Narita M: Spatial coupling of mTOR and autophagy augments secretory phenotypes. Science 332: 966-970, 2011

46 Nikoletopoulou V, Markaki M, Palikaras K and Tavernarakis N: Crosstalk between apoptosis, necrosis and autophagy. Biochim Biophys Acta 1833: 3448-3459, 2013.

47 Kaczmarek A, Vandenabeele P and Krysko DV: Necroptosis: The release of damage-associated molecular patterns and its physiological relevance. Immunity 38: 209-223, 2013.

48 Drullion C: Apoptosis and autophagy have opposite roles on imatinib-induced K562 leukemia cell senescence. Cell Death Dis 3: e373, 2012.

49 Gordon RR and Nelson PS: Cellular senescence and cancer chemotherapy resistance. Drug Resist Updat 15: 123-131, 2012.

50 Medema JP: Escape from senescence boosts tumour growth. Nature 553: 37-38, 2018.

$51 \mathrm{Hu} \mathrm{P}$ : Autophagy suppresses proliferation of HepG2 cells via inhibiting glypican-3/wnt/ $\beta$-catenin signaling. Onco Targets Ther 11: 193-200, 2018.

52 Baehrecke EH: Autophagy: dual roles in life and death? Nat Rev Mol Cell Biol 6: 505-510, 2005.

53 You L, Jin S, Zhu L and Qian W: Autophagy, autophagyassociated adaptive immune responses and its role in hematologic malignancies. Oncotarget 8: 12374-12388, 2017.

54 Chen Q, Kang J and Fu C: The independence of and associations among apoptosis, autophagy, and necrosis. Signal Transduct Target Ther 3: 18, 2018
Received October 28, 2018

Revised November 30, 2018

Accepted December 4, 2018 